\title{
EL LOGOS COMO PRINCIPIO DE UNIDAD DEL SER. UNA CONSIDERACIÓN ONTOLÓGICA A PARTIR DE LA PERSPECTIVA DE EDUARDO NICOL
}

\author{
Roberto Andrés González Hinojosa \\ bttps://orcid.org/0000-0003-4304-7311 \\ Universidad Autónoma del Estado de México \\ bttp://dx.doi.org/10.15304/ag.39.2.6298
}

\section{Resumen}

La presente investigación gira en tono al ser a partir de la perspectiva de Eduardo Nicol. Se ha intentado tematizar la nota de la unidad ontológica precisamente desde la distinción (y unidad) entre el logos y lo ajeno. Esta distinción posee una doble importancia, pues, por un lado, puede hablarse del inicio de esta forma de ser caracterizada por el simbolismo y el sentido; mientras que, por otro, esa misma distinción nos abrirá el camino hacia la eminencia de la unidad del ser.

Palabras clave: ser, Nicol, logos, ente, diferencia.

\section{Abstract}

The present investigation turns about the being from the perspective of Eduardo Nicol. An attempt has been made to thematize the note of the ontological unit precisely based on the distinction (and unity) between logos and others. This distinction has a double importance, because on the one hand, one can speak of beginning of this way of being characterized by meaning and symbolism; while on the other, that same distinction will open the way to the unity of being.

Keywords: being, Nicol, logos, entity, difference.

Recibido: 23/09/2019. Aceptado: 18/02/2020. 


\section{Introducción}

La presente investigación versa acerca del ser y el logos a partir de la perspectiva de Eduardo Nicol. Dice Horneffer, "ya desde sus primeros libros está claro cuál es el tema capital del pensamiento de Nicol: el ser" ${ }^{1}$. Esto es, la filosofía de nuestro autor se encuentra atravesada de principio a fin por la preocupación en torno al ser. El recurrente énfasis temático alrededor de éste es lo que nos lleva a firmar que esta filosofía constituye, sin duda, una ontología estricta. Semejante aseveración no se funda solo en la frecuencia con que el autor mienta el ser, sino, toda vía más, en el trato riguroso y parsimonioso que el catalán hace acerca del mismo. El presente trabajo constituye tan solo un botón de muestra de lo inmediatamente mencionado.

Eduardo Nicol nace en 1907 en Barcelona, España. En 1939, como producto de la guerra civil española, se ve obligado a emigrar hacia México. A partir de 1940 ingresa como catedrático en la Facultad de Filosofía y Letras de la Universidad Nacional Autónoma de México. El testamento filosófico del autor posee el mérito de haber sido escrito y publicado, casi en su totalidad, en castellano, el cual representa un baluarte sumamente importante que se atreve a caminar a contracorriente, criticando los relativismos emergentes en el pensamiento contemporáneo y a sugerir otra ruta teórica para los augustos problemas de la filosofía. El legado del autor catalán representa una suerte de veta que está aún a la espera del reconocimiento de la crítica contemporánea, pues, como bien lo ha dicho Adolfo Sánchez Vázquez: "el reconocimiento de la obra de Nicol..., no ha estado hasta ahora a la altura de sus merecimientos [por dos motivos], uno: es un filósofo exiliado que llega a México con un bagaje filosófico todavía incipiente... El otro hecho es el que sufre Nicol con los filósofos que publican en este mundo - ¿el llamado Tercer Mundo? - y que se encuentra en un plano de desigualdad con los que producen en los países desarrollados de Occidente" ${ }^{2}$. Nicol muere en 1990 en la Ciudad de México a los 82 años de edad, dejándonos una de las obras filosóficas más importantes en lengua española.

El objetivo de la presente investigación se encuentra enderezado hacia la exploración de la posibilidad temática de la unidad del ser, pero a partir precisamente de la esencial distinción entre el logos y lo ajeno. Esta posibili-

${ }^{1}$ Horneffer, Ricardo, "El fenómeno del misterio, o el misterio fenómeno-lógico", en Horneffer (coord.), Eduardo Nicol (1907-2007) Homenaje, México, UNAM, 2009, p. 336.

2 Sánchez Vázquez, Adolfo, "Palabras de reconocimiento a Eduardo Nicol", en El ser y la expresión (Juliana González y Lizbeth Sagols, eds.), México, UNAM, 1990, pp. 187-188. 
dad ha quedado esbozada en la obra del autor justamente cuando reconoce la datación del logos, precisamente ahí donde afirma que "el logos no ha existido desde siempre..., el logos vino a ser; su aparición representó un desdoblamiento del Ser" ${ }^{3}$, ocasionando con esto un enriquecimiento inusitado, toda vez que, a partir de este punto puede reconocerse el incremento del ser. Este enriquecimiento puede apreciarse por partida doble, a saber, por un lado, amanece un horizonte caracterizado por el simbolismo; mientras que, por otro lado, pueden comenzar a distinguirse dos relieves en el ser, esto es, el logos y lo dado. El autor dice que lo más inquietante, al versar acerca del logos y lo ajeno, no es tanto el dato de su separación, sino el fenómeno de su eminente reunión: "el dato es la unidad" ". Partiendo de esto, insistimos, se ha intentado mostrar la unidad del ser a partir justamente de la función del logos. Sostenemos, finalmente, que el logos, desde esta perspectiva, puede revelarse como el principio de unidad del ser.

La presente investigación ha pretendido formular un juicio sintético a partir de una lectura prolongada y crítica de la obra directa del autor catalán, el presente trabajo ha optado por un método dialéctico, en el sentido nicoliano del término, en virtud de que es resultado de un diálogo directo con el autor, en el cual hemos atravesado por ciertos pasajes significativos de su obra y afines con el objetivo mencionado.

\section{El punto de partida}

Consideramos que la indagación en torno a la relación entre el logos y el ser tiene que desprenderse precisamente desde su base original, aclarando que el punto de partida desde donde arranca la propuesta filosófica de $\mathrm{Ni}$ col viene envuelto en medio de un planteamiento sugerente y original. Toda vez que el autor, en un acto estratégico y metodológico, hace coincidir en un mismo punto la noción de comienzo y de fundamento. Desde luego, este planteamiento nos conduce hasta el origen desde donde se levanta la posibilidad misma de la existencia y del conocimiento. En torno a esto afirma: "la palabra principio, puede significar a la vez el comienzo y el fundamento; la base como punto de partida, y la base como sustento de lo que se construye sobre ella" ${ }^{5}$. Esto significa que, lo que haya de ser tenido como base

${ }^{3}$ Nicol, Eduardo, Crítica de la razón simbólica, México, FCE, 2001, pp. 258-259.

${ }^{4}$ Nicol, Eduardo, Formas de hablar sublimes, poesía y filosofía, México, UNAM, 1990, p. 40.

${ }^{5}$ Nicol, Eduardo, Los principios de la ciencia, México, FCE, 2001, p. 372. 
debe cumplir a un mismo tiempo una triple función; por un lado, constituir precisamente el punto de partida, en cuanto que pauta, de toda consideración teórica (esto es, el punto a partir del cual habrá de desprenderse la posibilidad de un planteamiento simbólico); mientras que por otro, éste debe ejercer la función de cimentación ontológica de la existencia (es decir, lo que es, irremisiblemente tendrá que estar sostenido justo sobre la base de este sustento); y en tercer lugar, éste ha de erigirse también en el fundamento del edificio del conocimiento en general. Desde luego, esta solicitud es demasiado ambiciosa, pues el autor no solo pretende dar respuesta al fundo del conocimiento, sino que también va de por medio la explicación de aquello que subyace en la base de la existencia. ¿Cómo logra Nicol dar salida a semejante solicitud?

La respuesta a este planteamiento es algo inusitada, pues, como se ha avizorado, el autor aclara que tanto el principio como el fundamento son satisfechos a cabalidad, simultáneamente, de una sola vez, el cual resulta, a todas luces, desde la perspectiva de Nicol, asequible por la experiencia común. En este punto, el autor va desplegar un giro radical a través del cual va a trastocar los supuestos tradicionales de la filosofía, toda vez que la solicitud tanto de principio como fundamento se verá satisfecha a través de un dato asequible a la experiencia común; en este punto el autor precisará distinguir entre las teorías y los hechos, acerca de lo cual va agregar: "las verdades de teoría son hipótesis: presuntas verdades. La verdad posible es un error posible" 6 , esto es, toda formulación de teoría siempre va a ser una creación lógica, por esto puede identificarse en primera instancia con una presunta verdad, o una hipótesis derivada. Mientras que los hechos no son una creación, no son algo derivado, sino un dato, y en cuanto que dato, punto de partida.

¿Cuál es, pues, el punto de partida en Nicol? Indudablemente es el ser. Este último, sin duda, representa el meollo de toda su obra. En torno a lo cual afirma: "el ser es el principio de todos los principios" ". Así también, en otra parte agrega: "Hemos encontrado pues el terreno firme que la filosofía ha requerido siempre.., el hecho de que hay ser. Este es el principio de todos los principios" tanto el comienzo de lo que es, así como el fundamento del conocimiento. Sin embargo, este aporte adquiere un aire completamente fresco cuando en la exposición del autor se enfatiza que este fundamento, como lo hemos

\footnotetext{
${ }^{6} \mathrm{Nicol}$, Eduardo, Ideas de vario linaje, México, UNAM, 1990, p. 334.

${ }^{7} \mathrm{Nicol}$, Crítica de la razón simbólica, p. 122.

${ }^{8}$ Nicol, Eduardo, Metafísica de la expresión, México, FCE, 1957, p. 126.
} 
anticipado, no es objeto de una búsqueda especial, como resultado de una hipótesis teorética, sino por el contrario, amanece ante todos como un hecho comúnmente asequible. Esto quiere decir que lo que se pone a la base en la filosofía de nuestro autor no es una hipótesis o teoría alguna, sino precisamente un hecho, a saber, el ser. Podría decirse que lo primero en el orden ontológico, así como en el orden epistemológico es justamente el ser. Este último, dice el autor, lejos de ser un problema, constituye más bien el dato, desde donde se levanta la posibilidad de toda ulterior búsqueda: "la evidencia universal de que hay ser, es el absoluto que se busca, y que no hay que buscar" , pues en el ser ya estamos desde luego y desde siempre.

\section{Anaximandro como punto de referencia}

Comenzamos aclarando que la alusión realizada aquí a Anaximandro obedece, ante todo, a una estrategia de carácter metodológico fundada principalmente en nuestras propias investigaciones, habida cuenta de que en la obra de Nicol es casi nula la presencia y alusión al autor de Mileto en cuestión. No obstante, el propósito de traer a colación a este pensador presocrático es para ponderar la semejanza de la imagen de su pensamiento con el propuesto por el autor catalán, para así dilucidar en lo que sigue la unidad del ser a partir precisamente de la función del logos.

Ahora bien, en lo concerniente al primer principio, mencionado más arriba, Nicol parece seguir a pie juntillas al viejo Anaximandro, quien en el alba de la filosofía afirmaba: "Ahi de donde emergen las cosas que existen, ahi mismo concluyen en su destrucción, de un modo necesario; pues se hacen justicia y reparación unas a otras de su injusticia según el orden del tiempo" ${ }^{10}$. En esta sentencia se acusan simultáneamente tres datos, a saber, por un lado, se reconoce la pluralidad del ente: este dato se recoge justo cuando se afirma que hay variedad de cosas que se extienden por lo largo y ancho en el espacio, es decir, hay un cosmos diversificado en una multiplicidad inagotable de particularidades, tendido ininterrumpidamente y dispuesto en diferentes relieves, colores, texturas, formas; acotándose cada

\footnotetext{
${ }^{9}$ Nicol, Los principios de la ciencia, p. 122.

${ }_{10}$ Anaximandro B 1, según versión de Eduardo Nicol; esta sentencia aparece en Los principios de la ciencia, p. 467. Así también, para cotejo de la misma, hemos traído la versión según Conrado Eggers, la cual reza de la siguiente manera: "A partir de donde hay generación para las cosas, hacia alli se produce también su destrucción, según la necesidad; en efecto, pagan la culpa unas a otras y la reparación de la injusticia, según el ordenamiento del tiempo" en Filósofos presocráticos I, Madrid, Biblioteca Clásica Gredos, 2001, p. 129.
} 
una al lado de la otra de un modo continuo en el horizonte del espacio. El autor de Mileto acusa este dato expresando que 'hay cosas' (los entes), es decir las cosas son múltiples, toda vez que se encuentran siendo, o sea, se encuentran extendiéndose en lo abierto del espacio, esta pluralidad de cosas es acusada por la experiencia común. Así también, el otro dato que se acusa aquí es precisamente el devenir. Éste es manifiesto justo cuando el milesio afirma que las cosas han venido a ser y que en algún momento del tiempo también dejarán de ser, esto (inicio y ocaso) sucede en el horizonte del devenir (conforme el orden del tiempo), es decir, la sentencia recoge y expresa que las cosas se encuentran en el claro de un proceso de transición, el cual dibuja una suerte de parábola la cual se extiende desde su irrupción a la existencia hasta su agotamiento y su destrucción, las cosas no están nunca en reposo, siempre se encuentran deviniendo, es decir, se encuentran en transición: el devenir es la sentencia, o sea, el castigo que todo ente está condenado a pagar uno con otro conforme el orden del tiempo. Esta disposición del ente no es creación de la razón, sino un dato que recoge la experiencia común. Esto significa que tanto la pluralidad como el devenir, lejos de ser una hipótesis, antes bien son hechos, o sean datos que marcan la pauta para el pensar. Ahora bien, aunado a estos dos datos o hechos (la pluralidad y la evanescencia del ente), Anaximandro realiza la proeza de atisbar mediante el pensamiento justamente aquello de donde emergen las cosas y donde sucumben en su destrucción (una vez que cada cual ha expiado sus culpas, esto es, una vez que el ente ha venido a ser, se ha desarrollado y ha sucumbido), pues donde sucede uno y lo otro es precisamente en uno y el mismo punto. Sin embargo, esto desde donde advienen los entes no es él mismo un ente más, es decir, no es reductible a una cosa entre las demás, pues si fuera así, entonces se tendría que buscar algún otro referente que permita explicar el origen y ocaso del ente; por lo tanto, aquello de donde viene las cosas, no patenta en sí la misma nota de lo advenido.

Amanece aquí, desde luego, una diferencia ontológica explícita. Nicol, aunque no está hablando de Anaximandro, nos ayuda a entender esta diferencia precisamente cuando dice que "el ente es lo contingente, el ente es limitado. Es el ser definido, cuya unidad se ofrece como determinación"11. Esto es, en la diferencia es posible distinguir con todo rigor el ente cuya nota está caracterizada justamente por la finitud en tanto que ha venido a ser, pero junto a esto finito se atisba algo otro, a lo que nos hace remisión lo contingente, desde donde cada finito ha venido a ser posible en su deter-

\footnotetext{
${ }^{11}$ Nicol, Eduardo, La idea del hombre, nueva versión, México, FCE, 2003, p. 66.
} 
minación; permitiendo avizorar algo que no ha venido a la existencia como producto de una posibilidad, sino, por contraste, siempre habría sido lo que es; el catalán afirma: "la razón de todo lo que existe es el absoluto..., el absoluto es el Ser" ${ }^{12}$.

Para entender un poco más esto es necesario advertir dos puntos: en primer lugar, la nota que distingue y de suyo le pertenece al ente es la determinación, tanto en el orden espacial, como en el orden temporal, es decir, el ente es el ser que aparece invariablemente como lo determinado; esto se entiende, en virtud de que cada cosa en algún momento del tiempo ha venido a ser y en algún momento también dejará de ser, amén de que cada cosa está en todo momento siendo constreñida por algún otro ente y a la vez ésta constriñe espacialmente a otros entes. En segundo lugar, por contraste de esto, Anaximandro advierte que hay algo que, sin ser un ente, no obstante, también es y por consecuencia la nota que le distingue, lejos de ser la determinación, es más bien la indeterminación. Esta última nota (lo indeterminado) constituye la pieza crucial bajo la cual la filosofía se atreve a dar el paso decisivo hacia la ciencia primera, la que posteriormente en Aristóteles se denominará metafísica, la cual versa acerca del ser en cuanto que ser. El autor de Mileto establece con todo rigor las bases para la posibilidad ontológica de la diferencia entre el ser y el ente. Pues si bien el ente es determinado, el ser es indeterminado, esto es, el ser no posee un origen, siempre ha sido y será, no conoce confín y no está delimitado por algo otro. En esta alba, el pensamiento es llevado a desplegar la experiencia original de la unidad fundamental, es decir, el ser se revela como único y sin oposición: el ser es uno.

\section{El enriquecimiento del ser y la irrupción del logos}

Ahora bien, de esto último nos interesa subrayar lo siguiente, Anaximandro deja en claro que lo que es, ha venido precisamente a ser en el claro del ser, y en este mismo (en el ser) en algún momento, así como advino, también dejará de ser: el concierto que se yergue entre el intervalo del nacimiento y el ocaso de lo que es, tiene lugar en el ser. El ser no mengua con el crepúsculo de un ente, al contrario, amanecen en éste, cada vez, nuevas formas y texturas dispares. Y en este punto es justamente donde Anaximandro conecta con Nicol, pues al igual que el de Mileto, el catalán piensa que

${ }^{12}$ Nicol, Ibid, pp. 70, 65. 
el ser es el claro ontológico para la novedad, toda vez que en el ser acaece la irrupción de toda posible existencia.

De entre todos los relieves del ser, hay uno que goza de especial interés y relevancia en la filosofía de Nicol, el cual, aun cuando comparte la nota de la finitud, posee no obstante una eminencia ontológica, pues mediante la función de esta forma de ser el autor podrá mostrar, de una manera dinámica, la unidad precisamente del ser. Esta singular forma de ser también en algún momento ha irrumpido en el ser, no obstante, su arribo ha representado, sin más, el acontecimiento lógico y ontológico por antonomasia. En alguna parte de su obra el filósofo catalán realiza la siguiente aseveración: "de repente un buen día, el Ser saca de sí mismo [al logos]"13. Corroborando con esta aseveración dos cosas; en primer lugar, se reitera que el ser constituye el horizonte para el advenimiento de cualquier forma de existencia posible, y en segundo lugar, queda de manifiesto que el ser posee de suyo una tendencia, si bien no hacia la complejidad propiamente dicha, sí hacia un autoenriquecimiento tácito.

Esto puede avizorarse tan pronto nos percatamos de que a partir del afloramiento de este logos se van a desplegar tres principales consecuencias en el seno mismo del ser, a saber:

(A) En primer lugar, el ser se enriquece ganando, o sumando, otra forma inédita de $\operatorname{ser}^{14}$, pues, desde esta perspectiva, el logos viene a aumentar cualitativamente, y en número, los relieves de sí. Éste constituye una forma de ser diferente a lo que existe bajo la forma de la extensión. Podría decirse que, en algún momento dado, el ser saca de sí esta otra forma de ser in-extensa y locuaz, sentando con ello el germen para un nuevo universo

${ }^{13}$ Nicol, Crítica de la razón simbólica, p. 259.

${ }^{14}$ Para Nicol, la forma de ser que precede al logos es precisamente la materia, en torno a esto dice: "la materia está en la génesis del logos como antecedente único, y está presente en cada uno de sus actos" (Ibid, p. 259). Con esta alusión de la materia como precedente del logos, la filosofía nicoliana es llevada hasta el borde de dos umbrales temáticos los cuales se antojan cuasi imposibles o, para decirlo llanamente, muy complicados: el primero de estos umbrales consistiría en que la razón es llevada a acariciar los confines de sus límites epistemológicos (o fenomenológicos), pues como bien lo reconoce el catalán, el desprendimiento del logos de una realidad ilógica sería un completo misterio. Esto último constituye el misterio de la materia, acerca del cual puede hablarse especulativamente, pero no resolverse teóricamente. Este tópico lo trata exhaustivamente en su libro Critica de la razón simbólica, pp. 256ss. Y el segundo umbral, o sea, la otra posibilidad ontológica que se desprende como un hecho de suyo, y que amanece también como alternativa temática de esta alusión, es justamente la que se refiere a la permanente reunión y separación entre el logos y lo ajeno, la cual, si bien no puede terminar de explicarse, sí puede constituir la pauta para conducir el pensamiento hacia la experiencia de la unidad del ser. 
simbólico, matizado, entre otras cosas, por el dinamismo y renovación permanente.

(B) En segundo lugar, a partir de esta irrupción puede establecerse con toda claridad la distinción entre dos formas de ser, esto es, entre el logos y lo ajeno. El autor dice: "su aparición [del logos] representó un desdoblamiento del ser y alteró, por tanto, un orden que había permanecido mudo" ${ }^{15}$. El logos vino hacer luz sobre todo aquello que habría permanecido sordo y a oscuras. El logos viene a iluminar mediante su función simbólica lo dado, haciendo más que visible la diferencia entre estas dos modalidades del ser.

(C) En tercer lugar, esta irrupción permitirá, en lo que sigue, el despliegue de un movimiento casi sinfónico, en el cual se van intercalando continuamente una separación y una reunión entre dispares; esto es, la separación y reunión entre lo lógico y lo no lógico. Esta reunión y separación, dice el autor, "se reproduce cada vez que se efectúa una operación simbólica". ${ }^{16}$ $\mathrm{Y}$, a decir verdad, desde nuestro punto de vista, este último constituye el camino temático que conduce, sin más, hacia la experiencia fundamental de la unidad del ser.

\section{III.1 Hay más ser}

Para entender un poco más esto, tratemos de abonar algunos detalles en cada uno de los tres puntos inmediatamente mencionados. En torno al primero, puede mencionarse que el logos se encuentra signado como una posibilidad, toda vez que su presencia acusa una datación en el tiempo y, como consecuencia (como ya decía Anaximandro acerca de lo contingente), así como vino a ser, también puede dejar de ser: "el logos vino a ser, [en virtud de que] no ha existido desde siempre" ${ }^{17}$. Éste trae consigo la nota de lo posible, es decir, de lo que no es necesario, adquiriendo con ello una cualidad verdaderamente excelsa, habida cuenta de que posee "la doble posibilidad negativa: el no- ser de lo que pudo haber sido, y el no-ser de lo que puede dejar de ser" ${ }^{18}$. No obstante, es excelso, no solo porque lleva en sí esta doble nota del no-ser, sino aún más, porque ha traído consigo un abanico inmenso de posibilidades latentes que se desperdigan y se desplazan por diferentes caminos simbólicos. El logos siempre se encuentra en movimiento renovándose e incrementándose, desde luego, en el claro del ser.

\footnotetext{
${ }^{15}$ Nicol, Ibid, p. 259.

${ }^{16}$ Nicol, Ibid, p. 264.

${ }^{17} \mathrm{Nicol}$, Ibid, p. 258.

${ }^{18}$ Nicol, Ibid, p. 260.
} 
Dice Nicol que la aparición del logos introduce un enriquecimiento sin paralelo en el interior del mismo ser, pues amanece una forma inagotable de posibilidades allende la necesidad natural. Esto representa un efectivo plus, habida cuenta de que florece literalmente un nuevo universo caracterizado por el sentido y por la diversidad de expresiones, cuyo principio no se encuentra acotado por la extensión de la materia ni la necesidad natural, sino antes bien en lo abierto de la libertad. Este nuevo universo, que amanece con el logos, queda de manifiesto por el conjunto de manifestaciones espirituales desplegadas en diferentes direcciones en todas las latitudes de la cultura y en el transcurso del tiempo. Evidentemente, la irrupción de la 'palabra' introduce otro modo de ser, que antes el universo no poseía, esta nueva forma de ser se encuentra cargada de sonoridad y significado, trastocando continuamente y de un modo inconmensurable la realidad circundante $^{19}$. En torno a esto, el autor agrega: "Hay más ser desde que puede hablarse del ser" ${ }^{20}$; es decir, tan pronto se materializa la posibilidad de hablar, éste se despliega experimentando un efectivo incremento, pues la palabra, lejos de ser algo natural, es, ante todo, una creación, la cual se añade a lo dado; es decir, es un plus que la naturaleza no ha puesto, sino por el contrario, solo por la función simbólica del logos, se puede ir más allá de lo puramente natural.

Cabe aclarar que para Nicol el hombre es propiamente el ser del logos, "en el hombre, el ser se hace logos, [al tiempo que] el logos se hace ser" 21 y, precisamente al ser éste el ser de la palabra, literalmente es un ser sobrenatural, justamente porque puede atreverse a comulgar con lo ajeno, de hecho es el único ser quien en cada situación se encuentra relacionado, es decir, se encuentra en comunión consigo, con sus semejantes y con lo

\footnotetext{
${ }^{19}$ En uno de sus textos, Nicol muestra que mediante la función simbólica del pensamiento la realidad se trastoca de dos modos, los cuales se suceden simultáneamente, a saber, por un lado, el sujeto que enarbola o concibe una idea acerca de sí o de lo dado, por el simple hecho de concebirla, ya está siendo otro, es decir, ha efectuado una mutación interna de su ser; y por otro lado, al ser este sujeto parte de la realidad, y al haberse transformado por la praxis del pensamiento, esa realidad circundante también se ha mutado efectivamente: “pues el propio conocer ya es un hacer. Éste no es, pues, un conocimiento cualquiera, sino el conocimiento que versa sobre el ser cognoscente, como la praxis virtuosa re-vierte sobre el ser actuante" (Nicol, La primera teoría de la praxis, México, UNAM, 1978, p. 51). Lo ajeno mismo, ha adquirido por causa de esta praxis otra dimensión cargada de un nuevo significado, pues si bien antes pudo haber estado ahí de una manera indiferente, ahora se descubre bajo un nuevo sentido, esto es, el que le confiere el ser simbólico.

${ }^{20}$ Nicol, Eduardo, Metafísica de la expresión, nueva versión, México, FCE, 1974, p. 130.

${ }^{21}$ Nicol, Ibid, p. 128.
} 
ajeno $^{22}$. Dice el autor: "hay una parte del ser que habla del ser, y que, al hablar, lo diversifica y lo enriquece inacabablemente" ${ }^{23}$. Mediante cada palabra el ser se diversifica inacabadamente, precisamente porque cada símbolo introduce una diferencia que mienta al ser en cierta situación específica, acusando un nuevo estatus, o mejor dicho, subrayando y provocando una nueva posición del ente; el logos se expresa en cada momento de una manera singular, y al hacerlo no solo altera al ser de la palabra, también conmueve el ámbito de realidad donde la palabra mienta el ser. Podría decirse que el ser del logos articula cada una de sus expresiones una sola vez, es decir, cada expresión es, sin duda, singular e irrepetible, por lo mismo, tan pronto ha sido articulada, inmediatamente se ve en la necesidad de volver a replantear su pronunciación de una manera inacabada, precisamente por esto el autor afirma que esa parte del ser que habla del ser, al hablar, lo diversifica y lo enriquece perpetuamente tejiendo un abanico inagotable de manifestaciones espirituales por distintas direcciones.

\section{III.2 Distinción entre dos formas del ser}

Ahora bien, en torno al segundo punto, dice el autor que la irrupción del logos vino hacer más que patente la distinción de dos formas de ser que, fenomenológicamente, resultan irreductibles entre sí, a saber, el logos y lo ajeno. Nicol afirma:

Se establece por ella una radical distinción entre dos órdenes del ser. Éstos no son la extensión y el pensamiento mudo. Son el hombre, en la integridad de su ser, con el logos prominente, con su ámbito mundano y con su historia, frente a todo lo que no es humano ${ }^{24}$.

Esto significa que la irrupción mentada habría venido a ponderar la distinción, o sea la diferencia, precisamente entre lo propio y lo ajeno. El logos, de acuerdo con el autor catalán, tiene que ver justamente con el hombre en su integridad, el cual se encuentra situado en un contexto específico en el mundo; mientras que lo ajeno, es precisamente eso (lo que no es humano), lo diferente, lo que se opone, o lo que le sale al paso. Aquí se puede afirmar que el autor ha traído a colación una modalidad temática más acerca de la

${ }^{22}$ Nicol afirma que el ser humano jamás puede dejar de estar en medio del claro de una relación vital, es decir, no puede desplegarse sino en el marco de sus relaciones; éste está circunscrito por tres extremos que no es él mismo: "el hombre puede relacionarse consigo mismo, con el prójimo, con la naturaleza y con la divinidad" (Nicol, La idea del hombre, nueva versión, p. 29).

${ }^{23} \mathrm{Nicol}$, Metafísica de la expresión, nueva versión, p. 128.

${ }^{24}$ Nicol, Critica de la razón simbólica, p. 261. 
diferencia, la cual amanece como dato primero en la facticidad del hombre en el mundo, esto quiere decir, el hombre existe diferenciándose de lo que no es él mismo, justo por esto es un ser de relaciones.

Con todo, esta irrupción, sin duda, ha representado el acontecimiento cósmico por antonomasia, pues, su aparición conmovió la eterna estabilidad del ser, en virtud de que, de repente la luminosidad del logos descubre la diversidad del ser. En otra parte el autor agrega lo siguiente: "Las notas constitutivas de esas dos formas son incompatibles. Esa del logos es una de las dos que conocemos; su aparición representó el desdoblamiento del ser y alteró, por tanto, un orden que había permanecido mudo desde la eternidad"25. El logos viene a iluminar lo dado. Esto es, mediante la función simbólica del logos lo ajeno comienza a adquirir rostro, comienza a mentarse, el ente finalmente puede constituirse precisamente en ente, pues al nombrarse adquiere entidad y puede ser objeto de referencia. El hombre va encontrado su sitio en el mundo al nombrar lo que le contorna, el mundo se le va descubriendo hasta tornarse familiar, se diría que lo ajeno es el correlato del hombre, y por esto éste siempre se encuentra en medio de lo dado ejerciendo una función sublime, a saber, la de hablar del ser, y mediante este ejercicio lógico el hombre va incorporando lo dado a su mundo.

Antes de ahondar un poco en este último punto, insistamos en que el desdoblamiento del ser data, así mismo, el desvelamiento, o aparición, del ente propiamente dicho. Esto puede entenderse, en virtud de que debido a la función simbólica del logos, lo ajeno comienza a perder su dejo de extrañeza, pues en la medida en que el logos cubre a lo dado lo va, asimismo, convirtiendo en algo asequible y lo va asumiendo en parte del mundo, es decir, el logos, al mentar lo ajeno, lo va volviendo justamente en la referencia, o correlato, de su existencia, trastocando a lo extraño en su contexto circundante en el mundo: el hombre queda instalado en medio de las cosas y mediante la función simbólica adquiere un lugar ontológicamente estratégico, en virtud de que al fin amanece una parte del ser que puede

${ }^{25}$ Nicol, Crítica de la razón simbólica, p. 259. Cabe agregar que de estas formulaciones que plantea Nicol, en torno a la relación entre el logos y lo ajeno, puede desprenderse la posibilidad para la factura de diferentes indagaciones de corte antropológico y ontológico, las cuales pueden abordarse sistemáticamente y de un modo sostenido. Problemas tales como: la fisonomía del misterio del logos y el ser; el asunto de la 'presencia' y 'pre-presencia' del ser; los límites de los alcances epistemológicos del logos; el bosquejo mismo de la diferencia entre lo desconocido y el misterio; etc. En la presente investigación, se ha puesto énfasis en dos cosas, a saber, que mediante la irrupción del logos el ser se ve enriquecido y, al mismo tiempo que se ve enriquecido, también puede apreciarse el desvelamiento tácito de dos relieves del ser, estos son el logos y lo ajeno. 
precisamente hablar del ser. Aquí es justo donde se puede datar el ente en cuanto que ente, pues a partir de aquí puede en efecto ser fijada la entidad de lo dado mediante una función simbólica, es decir, lo dado puede ser presentado ${ }^{26}$ precisamente mediante un acto lógico. Justamente por esto el autor acota: "El objeto no se constituye como real, no adquiere para mí su auténtica objetividad, con la certidumbre que no depende de mí solo, sino con la palabra" ${ }^{27}$. Y a esto es a lo que nos referimos cuando decimos que lo ajeno, por el logos, va adquiriendo rostro; es decir, se ilumina o, en otras palabras, se va descubriendo en su unidad entitativa. El hombre es el ser que habla del ser; éste es el ser simbólico por antonomasia justo porque existe simbolizando, y significando, lo que le va saliendo al paso.

\section{III.3 De la unidad dinámica del ser}

Ahora bien, pasemos al tercero y último punto. Consideramos que uno de los aportes de la filosofía del autor mexicano-catalán, al hablar de estos dos órdenes del ser (el logos y lo ajeno), lejos de enfatizar únicamente la irreductibilidad (o diferencia) de las notas entre estas dos formas, consiste en que se atreve a dar un paso más hacia adelante, avizorando un camino inusitado hacia el encuentro o reunión sincronizada de éstas, mostrando con ello de una manera ingeniosa la unidad precisamente del ser. Si bien el advenimiento del logos ha ocasionado un enriquecimiento y, sobre todo, un desdoblamiento del ser; el autor va a encontrar justo en la labor del logos la clave para que, sin perder su propia forma específica de ser, cada relieve, sin embargo, pueda ser conducida hasta el encuentro con la otra forma de ser respectivamente, dibujando una sincronía en la estructura interna del ser mismo.

En este punto, el pensamiento es conducido hasta el umbral en el que lo múltiple se ve imbricado, merced de la función simbólica del logos. Es decir, aquí es donde podemos avizorar la efectiva implicación de lo que es, a partir precisamente del logos. En abono a esto, Nicol afirma: "el logos distingue y reúne" ${ }^{28}$. Esto es, al distinguir, el logos se reúne; y viceversa, al reunirse, también se distingue; ambas figuras se dibujan simultáneamente y al unísono: el ser al devenir se diversifica al tiempo que por el mismo fluir de

${ }^{26}$ El logos, en Nicol, posee de suyo una propiedad apofántica, la cual consiste en declarar, o mejor dicho, en presentar ante otro ser lógico el ser. En torno a esto afirma: "el logos común manifiesta el ser con absoluta garantía" (Nicol, Metafísica de la expresión, nueva versión, p. 110).

${ }^{27}$ Nicol, Ibid, p. 112.

${ }^{28}$ Nicol, La idea del hombre, nueva versión, p. 78. 
su pluralidad se imbrica en el mismo cambio. El logos se revela aquí como principio de unidad del ser. Esta imagen ontológica que desde aquí se esboza está matizada por el dinamismo; no obstante, este dinamismo es quien habrá de conectar en una línea directa al pensamiento hacia lo abierto de la experiencia de la unidad precisamente del ser.

De entrada, la propuesta parte del siguiente planteamiento: "esa separación y esa unión simultaneas se reproduce cada vez que se efectúa una operación simbólica" ${ }^{29}$. Este hallazgo realizado por nuestro autor, abre una vereda en la que se reconoce la posibilidad de la unidad sobre la base de la diversidad. Es decir, se subraya el momento justo en cual el logos y lo ajeno entretejen una suerte de concierto ontológico que se tiñe de movimientos acompasados, en donde se describen por doquier figuras que se siguen y que se entrelazan unas a otras de un modo continuo y de una forma singular, mostrando la unión y separación de las distintas formas del ser, en el orden del devenir. Estas figuras florecen interminablemente, sucediéndose unas a otras, manifestando un dinamismo continuo en el claro del ser. Este concierto descubre la génesis primordial de esta separación y de esta unión, revelando el proceso de su singularidad y novedad ilimitada, pues, como dice el autor, en la operación simbólica tiene lugar el misterio más grande del cosmos, el cual consiste en esa distinción y reunión simultánea.

La irrupción del logos trajo consigo el florecimiento de un nuevo mundo, sobrecogido por el sentido, mismo que se actualiza y renueva a través de cada acto simbólico. Este último acto es, por así decirlo, el punto crítico donde se revela este juego renovador, integrador e inagotable. El acto lógico aquí se vuelve topográfico, pues en éste puede localizarse, el momento justo en el cual sucede la verdad prístina de la presentación del ser, en virtud de que el ámbito de la verdad del ser es precisamente el logos. Dice el autor que "la verdad es la manifestación del ser" 30 . El ser es un hecho que está fuera de discusión, es decir, no es un misterio, tampoco es un problema, pues no es producto de una hipótesis teórica (no es una construcción de la razón). No obstante, si bien por una parte el ser es un hecho, también resulta cierto, por otra parte, que la evidencia de su presencia se adquiere siempre mediante un acto comunicativo o expresivo ${ }^{31}$, es decir, la verdad

${ }^{29}$ Nicol, Crítica de la razón simbólica, p. 262.

${ }^{30} \mathrm{Nicol}$, Los principios de la ciencia, p. 70.

${ }^{31}$ Es justo en el marco del proyecto del intento de una nueva fundamentación tanto para la ciencia primera como para las ciencias especiales donde Nicol realiza este hallazgo, el cual lo expone bajo los siguientes términos: "En el programa de la renovación de la ciencia primera tenía que figurar ante todo el restablecimiento de la evidencia del ser. Dicha ciencia 
no la consigue un individuo en solitario, sino conjuntamente en un proceso de diálogo con otro ser lógico. Esto último representa un trastocamiento a la teoría habitual del conocimiento, habida cuenta de que en Nicol "encontramos una crítica sistemática de todos los supuestos básicos que, desde Parménides, Platón y Aristóteles, habían hecho posibles todas las filosofías que depositaron su confianza en la razón" ${ }^{2}$, denunciando aquella teoría como insuficiente, en primer lugar porque depositó toda su confianza en una razón cuasi endiosada, y en segundo lugar, porque dejó fuera de su esquema al otro como punto referencia para el conocimiento.

Aquí cabe acotar lo siguiente, el hombre en la perspectiva de Nicol, por definición, es dialéctico, en virtud de que cada uno se encuentra abierto y frente al otro a quien puede llamar tú, "ambos términos son dialécticos porque son funcionalmente complementarios cuando se refieren al ser del ente" ${ }^{33}$. Es desde este punto de vista que el logos amanece como la morada de la verdad del ser. "La apófansis es una presentación [del ser]" ${ }^{34}$ que se factura siempre dialécticamente por un ser lógico frente otro ser simbólico. En torno a esto, Ricardo Horneffer agrega: "el logos es palabra y razón [es] aquello en lo que el ser se hace presente" ${ }^{35}$. Aquí cabe agregar un elemento más, en torno a esta postura, derivado precisamente de lo inmediatamente mencionado, a saber, para Nicol el logos es de suyo intencional, es decir, siempre es trans-logos. La evidencia del ser es algo que está en la base de toda simbolización posible, pero más aún, ésta no la adquiere un sujeto lógico aislado, sino que, siendo objeto de una experiencia común, se adquiere siempre mediante el concurso del otro (de otro sujeto), es decir, mediante un acto trans-lógico o, mejor dicho, mediante un acto simbólico.

Con todo, lo que aquí nos interesa es ponderar que, desde este punto de vista, podría decirse que el acto simbólico retiene de un modo ejemplar y permanente la distinción, o irreductibilidad, del logos con lo ajeno; pero al

puede denominarse metafísica de la expresión porque revela que esa evidencia, que es inmediata y común, se obtiene precisamente en un acto expresivo o comunicativo" (Metafísica de la expresión, nueva versión, p. 122).

${ }^{32}$ Constante, Alberto, "Nicol y Heidegger: ¿diálogo imposible?”, en Horneffer (coord.), Eduardo Nicol (1907-2007), Homenaje, p. 274.

${ }^{33}$ Nicol, Crítica de la razón simbólica, p. 191. Para el autor catalán, la noción de dialéctica es un adjetivo exclusivo del ser del hombre, pues mediante esta noción se acusa la operación natural de la razón: "la dialéctica no es una optativa teórica. Los hombres hablan dialécticamente, [es decir], el hombre es constitutivamente dia-léctico" (Ibid, p. 192).

${ }^{34}$ Nicol, Los principios de la ciencia, p. 71.

${ }^{35}$ Horneffer, "El fenómeno del misterio, o el misterio fenómeno-lógico", en Horneffer (coord.), Eduardo Nicol (1907-2007), Homenaje, p. 337. 
mismo tiempo subraya la inexorable unión de lo dispar en el ser. Habida cuenta de que aquí resulta evidente que se llevan a cabo dos operaciones conjuntas o, mejor dicho, simultáneas; éstas son, por una parte, la distinción, o separación, entre lo propio y lo ajeno, y a la vez la reunión efectiva entre el logos y lo dado. En suma: "Lo decisivo en la teoría del logos es observar que, con su función simbólica, el logos regresa a la materia de donde nació" ${ }^{36}$. Esto quiere decir que en cada acto simbólico se recrea la genealogía del logos, al separase de la materia, distinguiéndose, se vuelve al origen de donde partió. En cada acto, el logos se distingue de lo ajeno, pero a la vez se reúne con lo dado. En torno a esto último, el autor catalán concluye: lo crucial "ya no es tan solo el del origen y el de una separación entre dos 'sustancias' esencialmente distintas, sino el de su efectiva unión" ${ }^{37}$.

Desde la filosofía de Nicol se podría llegar a invertir el orden de la clásica cuestión, toda vez que, si bien la unidad habría representado una dificultad mayor para la filosofía, ahora aparecería más bien como un puerto común de partida. En este sentido, el autor agrega: "La revolución actual de la metafísica consiste en una inversión: el dato es la unión" 38 , y junto a éste también aparece el dato de la separación de lo diverso en el ser. Junto con Nicol, reconocemos que el ser es uno, "el Ser es la totalidad de lo real ¿pues qué otra cosa sería?... [en éste encontramos una] absoluta imposibilidad de un vacío" 39 . Enfatizamos, sin embargo, que el logos se patenta como principio de unidad del ser, toda vez que a través de éste se facturan tres reuniones, todas acaecen de un modo simultáneo, a saber, por un lado, se da la reunión entre dos sujetos parlantes, quienes al reunirse a versar sobre lo dado, hacen visible, en segundo lugar, la reunión entre lo propio y lo ajeno, o sea, la reunión entre los dos relieves del ser, y en tercer lugar, por este logos el ser se reúne y se autorrecoge en sí mismo, esto es, acaece una total convergencia consigo mismo y en sí mismo. No es casual que el mismo autor catalán afirme que con la irrupción del logos "el Ser empieza a hablar de sí mismo..., el Ser adquirió la autoconciencia" ${ }^{40}$. En suma, por el logos el ser concuerda y coincide consigo mismo.

\footnotetext{
${ }^{36} \mathrm{Nicol}$, Crítica de la razón simbólica, p. 256.

${ }^{37}$ Nicol, Ibid, p. 262.

${ }^{38}$ Nicol, Formas de hablar sublimes, poesía y filosofía, p. 40.

${ }^{39} \mathrm{Nicol}$, Crítica de la razón simbólica, p. 249.

${ }^{40}$ Nicol, Ibid, p. 275.
} 


\section{Conclusiones}

Para finalizar esta meditación, consideramos que, partiendo de esta imagen del ser dibujada a partir de Nicol, puede en efecto ahondarse un poco más en la unidad del ser, y no precisamente como un supuesto, sino como un proceso dinámico en el que se va distinguiendo, y juntando, a cada momento lo dispar. Aquí el pensamiento es conducido hacia la experiencia de la unidad ontológica. En virtud de que el ser ciertamente es uno, pues no posee oposición, no obstante, es uno también porque sus partes se entrelazan dinámicamente y permanecen solidariamente imbricadas. Tratemos de aclarar un poco esto. El ser es uno precisamente porque todo acaece en sí y, en efecto, sólo hay ser; y la unión de lo dispar queda eminentemente manifiesta por el logos: pues por este último se pone en marcha el doble movimiento de distinción y, sobre todo, de reunión entre las formas del ser. Reiteremos, el ser es uno no porque sea algo estático, sino porque en éste tiene lugar el concierto dinámico de una reunión continua entre los diferentes relieves, y al mentar al logos como aquello que se distingue de lo dado, también se pone en circulación la factura de la distinción de lo que hay, aunque en esta última distinción se revela sin más la imposible indesglosabilidad del ser, habida cuenda de que aquí es donde sucede la efectiva unión entre lo lógico y lo no-lógico; es decir, aquí arribamos a la idea de que mediante esta función el pensamiento puede avizorar un panorama en el que la unidad del ser se alcanza justamente mediante la reunión de los dispares. El logos amanece, sin duda, como el principio de esta unidad, en virtud de que por éste lo disperso queda imbricado en el seno mismo del ser, imposibilitando cualquier suerte de dislocación ontológica, e inhabilitando cualquier sospecha de un más allá. Y toda vía más, el ser es uno porque por el logos se mantiene reunido desde su propio centro; el ser se autorrecoge en sí mismo, y se posee a sí solo. Podría decirse que por el logos es el ser mismo quien, haciendo coincidir los dispares, concuerda consigo mismo ${ }^{41}$.

${ }^{41}$ Vale la pena mencionar aquí que existe en Nicol otra salida, de corte cuasi hegeliana, en torno a la unidad del ser, partiendo precisamente de la relación entre el logos y la materia, la cual el autor la ha expresado en los siguientes términos: "no podemos hablar del ser sino desde dentro... Es evidente que no se pueda hablar de nada sino desde el ser, esto significa que lo ajeno no es tan ajeno..., no sería posible hablar de la materia si ésta no permanece inserta en el logos" (Crítica de la razón simbólica, p. 272). Mediante el ser del logos, el ser es quien toma la palabra y comienza a hablarse a sí mismo y a sí solo, el logos amanece literalmente como la diánoia del ser, reafirmando, una vez más, la singularidad de éste. Con todo, vale la pena insistir, una vez más, que en la presente investigación nos ha parecido pertinente, y sustentable, la tematización de la unidad del ser partiendo de esta imagen como una continua actualización en lo abierto del contraste entre el logos y lo ajeno. Emergiendo así precisamente la idea del logos como principio de la unidad del ser. 
Consideramos, junto con el autor, que si bien el ser no es una invención de la razón; también resulta cierto que algunas de sus notas, como en este caso la unidad de éste, pueden desarrollarse temáticamente a partir de cierta pauta como lo ha sido precisamente la función del logos. La presente investigación podría concluir diciendo que, desde que hay logos (y solo por este último), puede, en efecto, comenzar a hablarse de una efectiva unidad ontológica promovida o producida por la eminente reunión entre el logos y lo ajeno. En el ser se llevan a cabo tres reuniones simultáneas, a saber, en primer lugar, la que se da entre los parlantes, en segundo lugar, la que se da entre el logos y lo ajeno, y en tercer lugar, solo por el logos el ser llega a concordar consigo mismo, toda vez que justamente el logos puede erigirse en la eminente diánoia del ser.

\section{Bibliografía}

Constante, Alberto, "Nicol y Heidegger: ¿diálogo imposible?”, en Horneffer (coord.), Eduardo Nicol (1907-2007), Homenaje, México, Universidad Nacional Autónoma de México, 2009.

Filósofos presocráticos I, versión castellana de Conrado Eggers Lan y Victoria E. Julia, Madrid, Biblioteca Clásica Gredos, 2001.

Horneffer, Ricardo, "El fenómeno del misterio, o el misterio fenómenológico", en Horneffer (coord.), Eduardo Nicol (1907-2007), Homenaje, México, Universidad Nacional Autónoma de México, 2009.

Nicol, Eduardo, Metafísica de la expresión, $1^{\mathrm{a}}$ ed. México, Fondo de Cultura Económica, 1957.

Nicol, Eduardo, Metafísica de la expresión, nueva versión, México, Fondo de Cultura Económica, 1974.

Nicol, Eduardo, La primera teoría de la praxis, México, Universidad Nacional Autónoma de México, 1978.

Nicol, Eduardo, Formas de hablar sublimes poesía y filosofía, México, Universidad Nacional Autónoma de México, 1990.

Nicol, Eduardo, Ideas de vario linaje, México, Universidad Nacional Autónoma de México, 1990.

Nicol, Eduardo, Crítica de la razón simbólica, México, Fondo de Cultura Económica, 2001.

Nicol, Eduardo, Los principios de la ciencia, México, Fondo de Cultura Económica, 2001. 
Nicol, Eduardo, La idea del hombre, nueva versión, México, Fondo de Cultura Económica, 2003.

Sánchez Vázquez, Adolfo, "Palabras de reconocimiento a Eduardo Nicol", en El ser y la expresión” (Juliana González y Lizbeth Sagols, eds.), México, Universidad Nacional Autónoma de México, 1990. 